\title{
STRATEGIC TRIALS TO DEFINE THE BEST AVAILABLE TREATMENT FOR NEONATAL AND PAEDIATRIC SEPSIS CAUSED BY CARBAPENEM RESISTANT ORGANISMS
}

Daniele Donà ${ }^{1,2}$, MD, PhD; Mike Sharland ${ }^{1}$, MD; Paul T. Heath ${ }^{1}$, MD; Laura Folgori ${ }^{1,3}$, MD

${ }^{1}$ Paediatric Infectious Disease Research Group, Institute for Infection and Immunity, St George's University of London, London, UK

${ }^{2}$ Division of Paediatric Infectious Diseases, Department for Woman and Child Health, University of Padua, Padua, Italy

${ }^{3}$ Paediatric Infectious Disease Unit, Department of Paediatrics, Luigi Sacco Hospital, University of Milan, Milan, Italy

Corresponding author: Laura Folgori

Mailing address: St George's University of London, Jenner Wing, Level 2, Room 2.215E, Cranmer Terrace, London, SW17 ORE, United Kingdom

E-mail address: Ifolgori@sgul.ac.uk

Telephone number: +442087254851

Funding: This study did not receive any direct funding.

Keywords: infant, newborn; child; Gram-negative bacteria; carbapenem-resistance; clinical trials.

Abbreviated title: Treatment of pediatric carbapenem-resistant sepsis

Running title: Pediatric carbapenem-resistant sepsis

Disclosures: The authors have no conflicts of interest or funding to disclose related to this manuscript 


\section{ABSTRACT}

The optimal standard of care for carbapenem-resistant bloodstream infections in children is currently unknown. This systematic review, aiming to define the best available treatments to be compared with new antibiotics in clinical trials, clearly points out the paucity of available data. The simplification and a wider harmonisation of study design are a global priority to inform the best strategies to treat these life-threatening infections in children. 


\section{BACKGROUND}

Despite progress on child mortality rates, severe bacterial infections still cause significant morbidity and mortality in children and neonates [1]. Due to the extensive use of carbapenems during the last decades, carbapenem-resistant organisms (CROs) bloodstream infections (BSIs) have become a critical global health challenge, especially in low and middle-income countries [2-3]. These infections are either acquired from the mother around the time of delivery, from the community or in a healthcare facility.

Despite this increasing burden, the optimal treatment for CRO infections is still unknown due to the paucity of large randomized clinical trials (CTs) evaluating the effectiveness of various therapeutic approaches [4-5]. Recommendations are mostly derived from case reports, small case series and cohort studies with high heterogeneity in the treatment options evaluated. In one study, combination therapy with at least two agents showed a significant reduction in mortality compared to monotherapy [6]. Antibiotics currently available for CRO infections include aminoglycosides, polymyxins, tigecycline and fosfomycin. Since their marketing approval, most of these old drugs have not been subject to modern drug development procedures and information on their clinical use are scarce with several important concerns about limited efficacy, increased resistance and specific toxicities [7].

Despite the fact that there are new agents for CRO registered or in late stage clinical development, the lack of definition for the best available treatment to be used as standard of care (SOC) hampers the conduct of properly-designed paediatric/neonatal CTs. Therefore, the aim of this study was to systematically review the published evidence on the effectiveness of the antibiotic regimens commonly used for CRO sepsis in children in the attempt to establish the best available SOC and inform the design of future CTs. 


\section{METHODS}

On the $5^{\text {th }}$ of September 2017, MEDLINE (Ovid MEDLINE(R) without Revisions 1996 to August Week 4 2017) and EMBASE (Embase 1996 to 2017 Week 36) databases were systematically searched using a strategy combining MeSH and free-text terms for antibiotics AND Gram-negatives AND resistance to carbapenems in children (age range 0-18 years). The full search strategy is available in the Supplementary data.

Studies published in English, German, Italian, French, Polish, Greek, Dutch, Hungarian, Portuguese and Spanish were considered for inclusion.

Studies reporting data on 1) the single-patient level outcome related to 2) a specific antibiotic treatment 3) for BSIs 4) caused by carbapenem-resistant Gram-negatives 5) in children were included. Studies reporting data on other (non-BSIs) infections were excluded. Studies reporting data from both adults and children were included only if single-child level information could be identified.

\section{RESULTS}

The search identified 5,246 papers of which 16 fulfilled both inclusion and exclusion criteria and were included in the analysis (Supplementary Figure 1) [8-23]. Overall, outcome data was available for 61 patients, 67\% (41/61) aged below than 3 months and 62\% (38/61) of which were neonates. All the patients included were admitted to Intensive Care Unit, and all were reported to have comorbidities. According to the 2018 World Bank Classification [24], 7 studies were carried out in high-income $[8-9,12,14,17-18,22]$ and 9 in middle-income countries [10-11, 13, 15-16, 19-21, 23]. Regarding the causative pathogens, 29 out of 62 isolates (one patient had 2 isolates) were Klebsiella pneumoniae, 22 Acinetobacter baumannii, 7 were Escherichia coli and 4 were Enterobacter cloacae. The genetic carbapenemase responsible for the resistance trait was available only for 38 isolates (Table 1).

27 out of 61 children (44\%) received monotherapy whereas $34(56 \%)$ were treated with a combination of two or more antibiotics. Overall, 27 different antibiotic regimens were reported, 8 
including one and 19 including multiple drugs. The most frequently used regimen included carbapenems plus polymyxins (12 out of 27). Information on dosing was available only for 3 out of 61 patients.

Among the entire cohort, the case fatality rate was $36 \%(22 / 61), 12$ of which were neonates (Box 1$)$. The mortality was higher in patients receiving monotherapy $(11 / 27,41 \%)$ compared with children treated with antibiotic combinations $(11 / 34,32 \%)$.

\section{DISCUSSION}

This study clearly points out the paucity of data available on the treatment for children with CRO BSIs. Single-patient data were available for 61 children only, with a very wide variation in the prescribed regimens.

Although being the most comprehensive review available on the topic, this study has several limitations. Firstly, the limited number of included papers and the very small sample size did not permit any statistical analysis. Secondly, due to the lack of specific information provided by the authors, it was not possible to distinguish empiric versus targeted treatment in the evaluation of patients' outcome. For the same reason, we could not stratify patients based on the concordance or discordance of treatment, as the single pathogens' full resistance profiles were rarely reported. We found a huge heterogeneity in the included studies in terms of study design, population and pathogens of interest. Lastly, because of the small sample size, all the Gram-negative organisms have been grouped together.

Considering the worldwide increase in antimicrobial resistance, the high mortality rates, and the very limited options available for treating these infections in children, the need to conduct CTs selectively on CRO in this population is now crucial to identify the best available treatment. However, CRO infections are rare in children in Europe, making an adequate sample size difficult to achieve. Second, enrolling a patient into a clinical trial with limited therapeutic options can raise ethical issues if the infecting pathogen is resistant to one of the comparator agents [25]. 
Even if CTs on new antibiotics are now mostly relying on a non-inferiority strategy, the design of antibacterial trials expecting to demonstrate a non-inferiority over the comparator is broadly unrealistic in case of non-susceptible multidrug-resistant (MDR) pathogens [26]. To overcome this problem, it has been suggested to design specific antibiotics CTs only focused on MDR infections. However, these studies might be difficult to design, are costly, and difficult to complete. Furthermore, being selected as a suitable centre to recruit to CTs of MDR infections, because of the high rate of antimicrobial resistance, may be of concern to specific institutions.

However, it is not feasible for antibacterial drugs that treat serious resistant bacterial infections to be developed using traditional, large scale CTs due to the limited numbers of patients in which these serious infections occur. For this reason, the Limited Population Antibacterial Drug (LPAD) mechanism, a new pathway to speed up patient access to critically-needed antibiotics, has been recently proposed for adults [27]. This pathway aims to overcome the problem of widespread untargeted use of new antibiotics, at the same time reducing the barriers to drug development and approval process by framing MDR infections as "orphan diseases". A drug's safety and effectiveness could therefore be studied in smaller, more rapid, and less expensive CTs in small, well-defined populations of patients for whom the drug's benefit has been shown to outweigh its risks [28].

Adult data on CRO treatment are also limited, and paediatric drug research is often based on smallscale studies that lack the statistical power necessary to draw any firm conclusion. However, the single dose PK single arm study approach that has been recently proposed is not sufficient here to inform the best available treatment [29]. In this case, CRO-focused strategic trials where the optimal drug combination can be studied using both off-patent and new antibiotics should be adopted. By using an all-comers approach, children of different ages with probable or proven CRO BSIs could be enrolled in a multi-dose study investigating the efficacy of different treatment regimens. This approach would also include neonates. If possible, adolescents should be included and enrolled in adult LPAD CTs, pooling controls across different age groups, and recruited globally. 
The treatment of paediatric CRO infections is a challenge worldwide, and the paucity of published data don't allow, at the moment, to establish the best available therapeutic scheme. A joint effort between the various stakeholders is crucial to overcome the multiple barriers to conducting CTs and guarantee safe and effective therapies. Paediatric and neonatal CTs using simple and standardised trial designs are now a global priority in order to inform the optimal management of these lifethreatening infections.

Funding: This study did not receive any direct funding. 


\section{REFERENCES}

1. GBD 2015 Child Mortality Collaborators. Global, regional, national, and selected subnational levels of stillbirths, neonatal, infant, and under-5 mortality, 1980-2015: a systematic analysis for the Global Burden of Disease Study 2015. Lancet. 2016; 388(10053): 1725-74.

2. Investigators of the Delhi Neonatal Infection Study (DeNIS) collaboration. Characterisation and antimicrobial resistance of sepsis pathogens in neonates born in tertiary care centres in Delhi, India: a cohort study. Lancet Glob Health. 2016; 4(10): e752-60.

3. Ozsurekci $\mathrm{Y}$, Aykac $\mathrm{K}$, Cengiz $\mathrm{AB}$, et al. Bloodstream infections in children caused by carbapenem-resistant versus carbapenem-susceptible gram-negative microorganisms: Risk factors and outcome. Diagn Microbiol Infect Dis. 2017; 87(4): 359-64.

4. Morrill HJ, Pogue JM, Kaye KS, LaPlante KL. Treatment Options for Carbapenem-Resistant Enterobacteriaceae Infections. Open Forum Infect Dis. 2015; 2(2): ofv050.

5. Paul M, Daikos GL, Durante-Mangoni E, et al. Colistin alone versus colistin plus meropenem for treatment of severe infections caused by carbapenem-resistant Gram-negative bacteria: an open-label, randomised controlled trial. Lancet Infect Dis. 2018; 18(4): 391-400.

6. Daikos GL, Tsaousi S, Tzouvelekis LS, et al. Carbapenemase-producing Klebsiella pneumoniae bloodstream infections: lowering mortality by antibiotic combination schemes and the role of carbapenems. Antimicrob Agents Chemother. 2014; 58(4): 2322-8.

7. Folgori L, Bielicki J, Heath PT, Sharland M. Antimicrobial-resistant Gram-negative infections in neonates: burden of disease and challenges in treatment. Curr Opin Infect Dis. 2017; 30(3): 281-8.

8. Bonfanti P, Bellu R, Principe L, et al. Mother-To-Child Transmission of KPC CarbapenemaseProducing Klebsiella Pneumoniae at Birth. Pediatr Infect Dis J. 2017; 36(2): 228-9. 
9. Dara JS, Chen L, Levi MH, Kreiswirth BN, Madan RP. Microbiological and genetic characterization of carbapenem-resistant Klebsiella pneumoniae isolated from pediatric patients. $J$ Pediatric Infect Dis Soc. 2014; 3(1): e10-e4.

10. Datta S, Roy $S$, Chatterjee $S$, et al. A five-year experience of carbapenem resistance in Enterobacteriaceae causing neonatal septicaemia: predominance of NDM-1. PLoS One. 2014; 9(11): p. e112101.

11. Escobar Perez JA, Olarte Escobar NM, Castro-Cardozo B, et al. Outbreak of NDM-1-producing Klebsiella pneumoniae in a neonatal unit in Colombia. Antimicrob Agents Chemother. 2013; 57(4): 1957-60.

12. Falagas ME, Sideri G, Vouloumanou EK, Papadatos JH, Kafetzis DA. Intravenous colistimethate (colistin) use in critically ill children without cystic fibrosis. Pediatr Infect Dis J. 2009; 28(2): 123-7.

13. Hurtado IC, Trujillo M, Restrepo A, Garces C, Tamayo C, Mesa JG. Experience with tigecycline compassionate use in pediatric patients infected with carbapenem resistant Klebsiella pneumoniae. Rev Chilena Infectol. 2012; 29(3): 317-21.

14. Lo A, Verrall R, Williams J, Stratton C, Della-Latta P, Tang YW. Carbapenem resistance via the blaKPC-2 gene in enterobacter cloacae blood culture isolate. South Med J. 2010; 103(5): 453-4.

15. Malande OO, du Plessis A, Rip D, Bamford C, Eley B. Invasive carbapenem-resistant Enterobacteriaceae infection at a paediatric hospital: A case series. S Afr Med J. 2016; 106(9): 87782.

16. de Oliveira MS, Costa SF, Pedri E, van der Heijden I, Levin AS. The minimal inhibitory concentration for sulbactam was not associated with the outcome of infections caused by carbapenem-resistant Acinetobacter sp. treated with ampicillin/sulbactam. Clinics (Sao Paulo). 2013; 68(4): 569-73. 
17. Oteo J, Hernandez-Almaraz JL, Gil-Anton J, et al. Outbreak of vim-1-carbapenemaseproducing enterobacter cloacae in a pediatric intensive care unit. Pediatr Infect Dis J. 2010; 29(12): 1144-6.

18. Pannaraj PS, Bard JD, Cerini C, Weissman SJ. Pediatric carbapenem-resistant Enterobacteriaceae in Los Angeles, California, a high-prevalence region in the United States. Pediatr Infect Dis J. 2015; 34(1): 11-6.

19. Qamar MU, Nahid F, Walsh TR, Kamran R, Zahra R. Prevalence and clinical burden of NDM-1 positive infections in pediatric and neonatal patients in Pakistan. Pediatr Infect Dis J. 2015; 34(4): 452-4.

20. Roy S, Viswanathan R, Singh AK, Das P, Basu S. Sepsis in neonates due to imipenem-resistant Klebsiella pneumoniae producing NDM-1 in India. J Antimicrob Chemother. 2011; 66(6): 1411-3.

21. Thatrimontrichai A, Apisarnthanarak A, Chanvitan P, Janjindamai W, Dissaneevate S, Maneenil G. Risk factors and outcomes of carbapenem-resistant Acinetobacter baumannii bacteremia in neonatal intensive care unit: a case-case-control study. Pediatr Infect Dis J. 2013; 32(2): 140-5.

22. Tsiatsiou O, losifidis E, Katragkou A, et al. Successful management of an outbreak due to carbapenem-resistant Acinetobacter baumannii in a neonatal intensive care unit. Eur J Pediatr. 2015; 174(1): 65-74

23. Zhang X, Li X, Wang M, et al. Outbreak of NDM-1-producing Klebsiella pneumoniae causing neonatal infection in a teaching hospital in mainland China. Antimicrob Agents Chemother. 2015; 59(7): 4349-51.

24. The World Bank. The World Bank list of economies. 2018. Available at: http://siteresources.worldbank.org/DATASTATISTICS/Resources/CLASS.XLS. Last accessed December 21, 2018. 
25. McDonnell A, Rex JH, Goossens H, Bonten M, Fowler VG Jr., Dane A. Efficient Delivery of Investigational Antibacterial Agents via Sustainable Clinical Trial Networks. Clin Infect Dis. 2016; 63 Suppl 2: S57-9.

26. European Medicine Agency. Addendum to the guideline on the evaluation of medicinal products indicated for treatment of bacterial infections (EMA/CHMP/351889/2013). Available at: http://www.ema.europa.eu/docs/en GB/document library/Scientific guideline/2013/11/WC50015 3953.pdf. Last accessed December 21, 2018.

27. Food and Drug Administration. Limited Population Pathway for Antibacterial and Antifungal Drugs. Guidance for Industry. Draft guidance. June 2018. Available at: https://www.fda.gov/downloads/Drugs/GuidanceComplianceRegulatorylnformation/Guidances/UC M610498.pdf. Last accessed December 21, 2018.

28. A Study of Plazomicin Compared With Colistin in Patients With Infection Due to Carbapenem-Resistant Enterobacteriaceae (CRE) (CARE). ClinicalTrials.gov Identifier: NCT01970371. Available at: https://clinicaltrials.gov/ct2/show/NCT01970371? cond=colistin+plazomicin\&rank=1. Last accessed January 24, 2019.

29. European Medicines Agency. Addendum to the guideline on the evaluation of medicinal products indicated for treatment of bacterial infections to address paediatric-specific clinical data requirements. (EMA/CHMP/187859/2017). Draft 2018. Available at: http://www.ema.europa.eu/docs/en GB/document library/Scientific guideline/2018/04/WC50024 7102.pdf. Last accessed January 24, 2019. 
Table 1: Characteristics of included studies

\begin{tabular}{|c|c|c|c|c|c|c|c|c|c|c|c|c|c|}
\hline $\begin{array}{l}\text { Study } \\
\mathrm{N}\end{array}$ & Author & Country & Study design & Age & $\begin{array}{l}\text { Types of } \\
\text { patients }\end{array}$ & CR* Pathogen & Carbapenemase & $\begin{array}{c}\text { Treatment } \\
1\end{array}$ & $\begin{array}{c}\text { Days of } \\
\text { treatment }\end{array}$ & $\begin{array}{c}\text { Treatment } \\
2\end{array}$ & $\begin{array}{c}\text { Days of } \\
\text { treatment }\end{array}$ & $\begin{array}{c}\text { Treatment } \\
3\end{array}$ & Outcome \\
\hline 1 & $\begin{array}{c}\text { Bonfanti P, } \\
2016[8]\end{array}$ & Italy & Case report & neonate & $\begin{array}{l}\text { Mother-to-child } \\
\text { transmitted at } \\
\text { birth-NICU** }\end{array}$ & K. pneumoniae & KPC & Colistin & 10 & Meropenem & 10 & & Survived \\
\hline \multirow[t]{2}{*}{2} & $\begin{array}{l}\text { Dara JS, } \\
2013 \text { [9] }\end{array}$ & US & Retrospective & 8 years & $\mathrm{PICU}^{* * *}$ & K. pneumoniae & . & Polymyxin B & 14 & Rifampin & 14 & & Survived \\
\hline & & & & 3 years & $\begin{array}{c}\text { Renal } \\
\text { transplanted }\end{array}$ & K. pneumoniae & & Polymyxin B & 14 & Rifampin & 14 & & Survived \\
\hline \multirow[t]{7}{*}{3} & $\begin{array}{c}\text { Datta S, } 2014 \\
{[10]}\end{array}$ & India & $\begin{array}{c}\text { Prospective } \\
\text { study }\end{array}$ & neonate & $\begin{array}{c}\text { Prematurity, } \\
\text { NICU }\end{array}$ & E. coli & NDM-1 & $\begin{array}{l}\text { Piperacillin- } \\
\text { tazobactam }\end{array}$ & . & Amikacin & . & . & Survived \\
\hline & & & & neonate & $\begin{array}{c}\text { Prematurity, } \\
\text { NICU }\end{array}$ & E.coli & NDM-1 & $\begin{array}{l}\text { Piperacillin- } \\
\text { tazobactam }\end{array}$ & & Amikacin & . & & Survived \\
\hline & & & & neonate & NICU & K. pneumoniae & NDM-1 & Colistin & . & . & . & & Survived \\
\hline & & & & neonate & $\begin{array}{c}\text { Prematurity, } \\
\text { NICU }\end{array}$ & K. pneumoniae & NDM-1 & Ofloxacin & . & . & . & & Survived \\
\hline & & & & neonate & $\begin{array}{c}\text { Prematurity, } \\
\text { NICU }\end{array}$ & K. pneumoniae & NDM-1 & Ofloxacin & . & . & & & Survived \\
\hline & & & & neonate & NICU & K. pneumoniae & NDM-1 & Colistin & . & . & . & & Survived \\
\hline & & & & neonate & $\begin{array}{c}\text { Prematurity, } \\
\text { NICU }\end{array}$ & E. coli & NDM-1 & Meropenem & . & . & . & & Dead \\
\hline
\end{tabular}




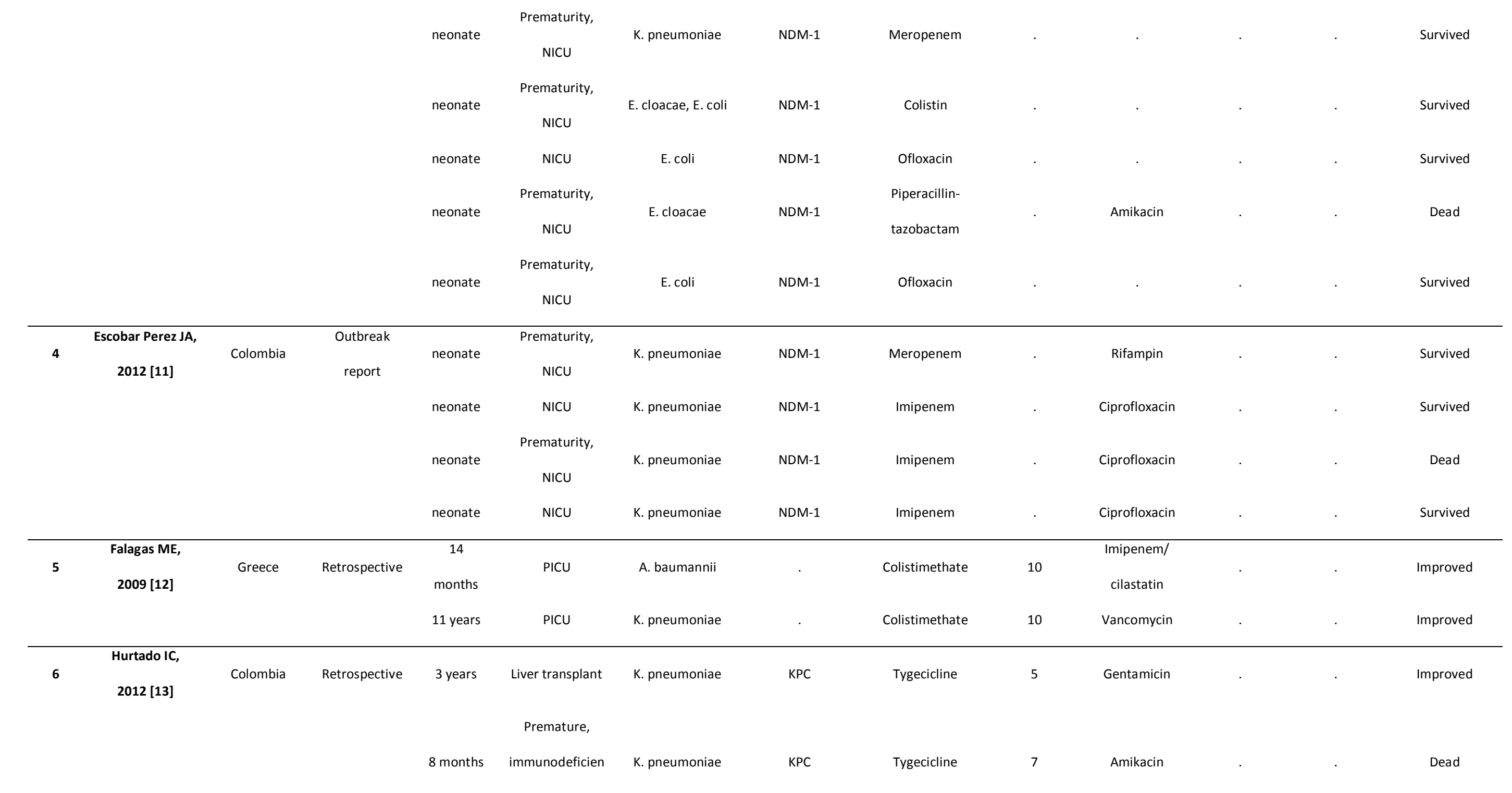




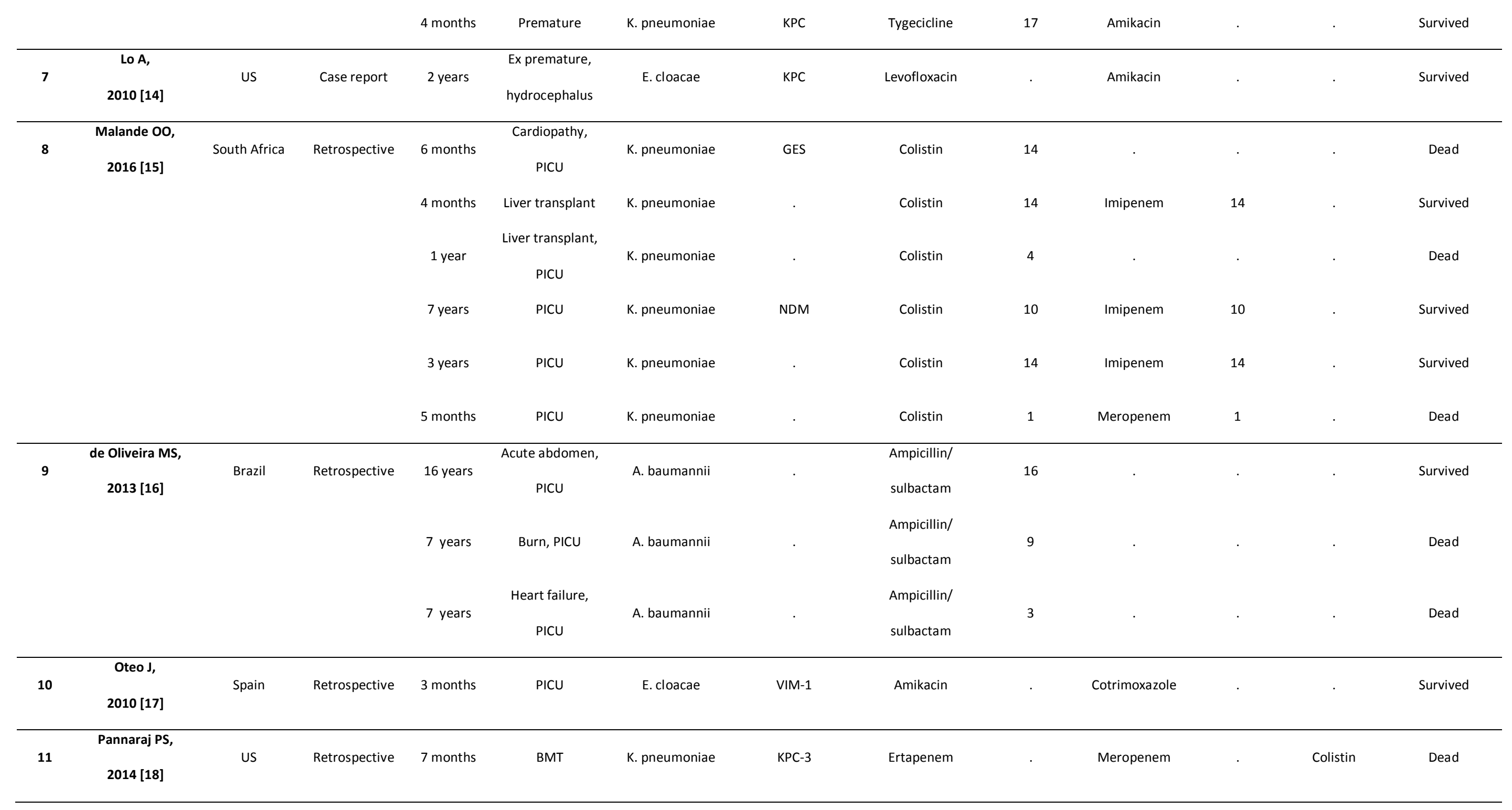




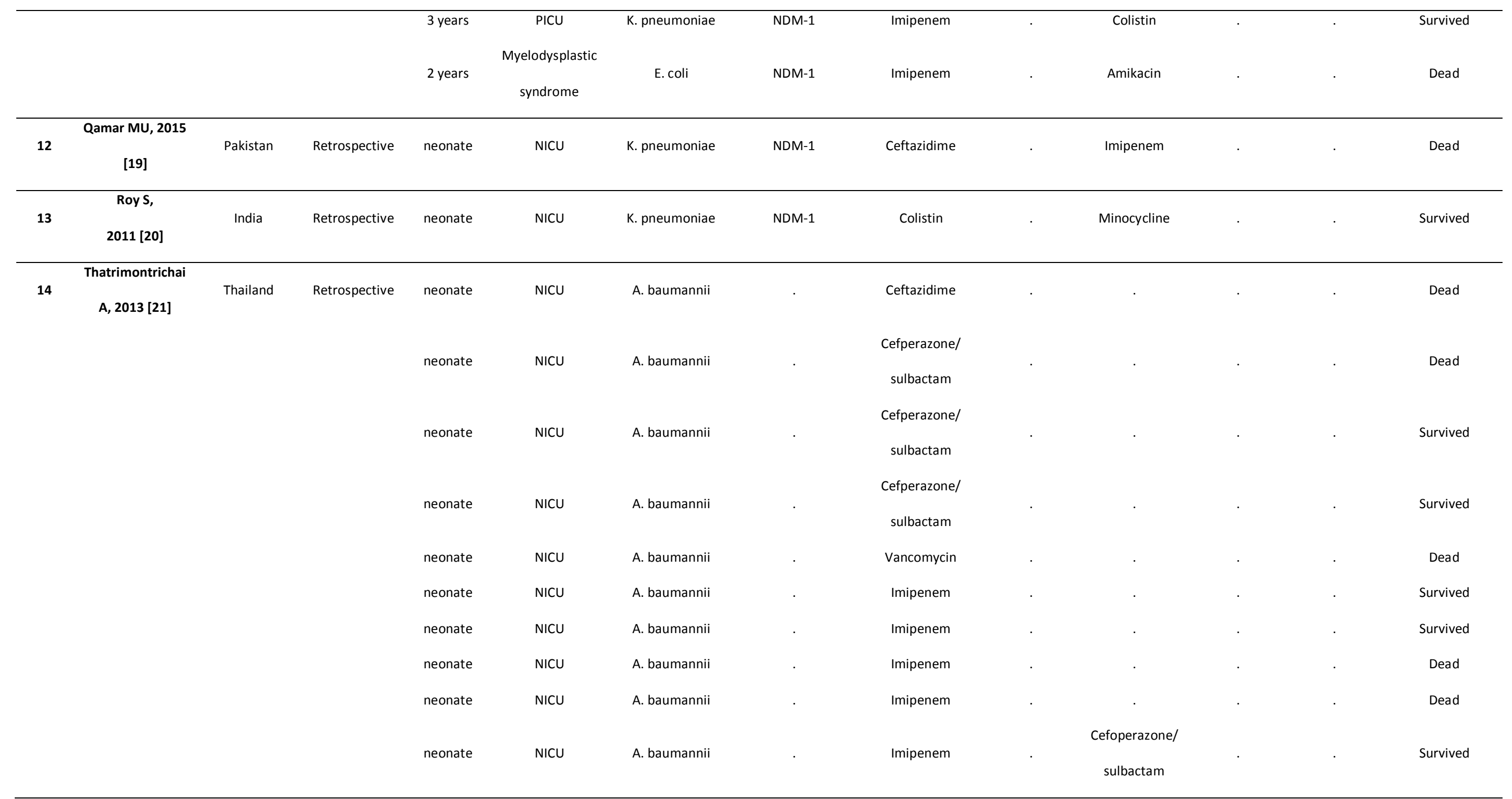




\begin{tabular}{|c|c|c|c|c|c|c|c|c|c|c|}
\hline & & & & neonate & NICU & A. baumannii & & Colistin & & Dead \\
\hline & & & & neonate & NICU & A. baumannii & & Colistin & & Survived \\
\hline & & & & neonate & NICU & A. baumannii & & Colistin & $\begin{array}{c}\text { Cefoperazone/ } \\
\text { sulbactam }\end{array}$ & Survived \\
\hline \multirow[t]{5}{*}{15} & $\begin{array}{c}\text { Tsiatsiou 0, } 2015 \\
\text { [21] }\end{array}$ & Greece & $\begin{array}{c}\text { Prospective } \\
\text { study }\end{array}$ & neonate & SGA, NICU & A. baumannii & $\begin{array}{l}\text { OXA-51-like and } \\
\text { OXA-58 }\end{array}$ & Meropenem & Colistin & Survived \\
\hline & & & & neonate & NICU & A. baumannii & $\begin{array}{c}\text { OXA-51-like and } \\
\text { OXA-58 }\end{array}$ & Meorpenem & . & Survived \\
\hline & & & & 6 weeks & $\begin{array}{c}\text { Prematurity, } \\
\text { NICU }\end{array}$ & A. baumannii & $\begin{array}{l}\text { OXA-51-like and } \\
\text { OXA-58 }\end{array}$ & Meropenem & Colistin & Survived \\
\hline & & & & neonate & $\begin{array}{l}\text { Prematurity, } \\
\text { NEC, NICU }\end{array}$ & A. baumannii & $\begin{array}{c}\text { OXA-51-like and } \\
\text { OXA-58 }\end{array}$ & Meropenem & Colistin & Survived \\
\hline & & & & 11 weeks & $\begin{array}{l}\text { Prematurity, } \\
\text { renal failure, } \\
\text { NICU }\end{array}$ & A. baumannii & $\begin{array}{l}\text { OXA-51-like and } \\
\text { OXA-58 }\end{array}$ & Meropenem & Colistin & Dead \\
\hline \multirow[t]{3}{*}{16} & $\begin{array}{l}\text { Zhang XY, } \\
2015 \text { [22] }\end{array}$ & China & Retrospective & neonate & NEC, NICU & K. pneumoniae & NDM-1 & Meropenem & Ciprofloxacin & Dead \\
\hline & & & & neonate & $\begin{array}{c}\text { Pneumonia, } \\
\text { NICU }\end{array}$ & K. pneumoniae & NDM-1 & Ceftazidime & . & Survived \\
\hline & & & & neonate & $\begin{array}{c}\text { Pneumonia, } \\
\text { NICU }\end{array}$ & K. pneumoniae & NDM-1 & $\begin{array}{l}\text { Piperacillin/ } \\
\text { tazobactam }\end{array}$ & Ceftazidime & Poor prognosis \\
\hline
\end{tabular}

${ }^{*}$ CR: carbapenem-resistant; ${ }^{* *}$ NICU: Neonatal Intensive Care Unit; ${ }^{* * * P I C U: ~ P a e d i a t r i c ~ I n t e n s i v e ~ C a r e ~ U n i t ~}$ 


\begin{tabular}{lcc}
\hline & N & Dead patients \\
\hline Total number & 38 & 12 \\
\hline Pathogen & & \\
K. pneumoniae & 15 & 4 \\
A. baumannii & 16 & 6 \\
E. coli & 6 & 1 \\
E. cloacae & 2 & 1 \\
\hline
\end{tabular}

\section{Treatment regimen}

$\begin{array}{lll}\text { Monotherapy } & 22 & 7\end{array}$

Combination $\quad 16 \quad 5$

\section{Antibiotics}

$\begin{array}{rll}\text { Polymyxins } & 5 & 1 \\ 3^{\text {rd }} \text { gen- cephalosporins } & 5 & 2 \\ \text { Glycopeptides } & 1 & 1 \\ \text { Carbapenems } & 7 & 3 \\ \text { Fluoroquinolones } & 4 & 0 \\ \text { Carbapenems + Polymyxins } & 3 & 0 \\ \text { Carbapenems + Rifampin } & 1 & 0 \\ \text { Carbapenems }+ \text { Fluoroquinolones } & 4 & 2 \\ 3^{\text {rd }} \text { gen- cephalosporins }+ \text { Carbapenems } & 2 & 1 \\ \text { Polymyxins }+ \text { Tetracyclines } & 1 & 0 \\ 3^{\text {rd }} \text { gen- cephalosporins }+ \text { Polymyxins } & 1 & 0 \\ \text { Pip-tazobactam }+ \text { Aminoglycosides } & 3 & 1 \\ \text { gen- cephalosporins }+ \text { Pip-tazobactam } & 1 & 1\end{array}$




\section{Supplementary digital content \\ STRATEGIC TRIALS TO DEFINE THE BEST AVAILABLE TREATMENT FOR NEONATAL AND \\ PAEDIATRIC SEPSIS CAUSED BY CARBAPENEM RESISTANT ORGANISMS}

Daniele Donà, Mike Sharland, Paul T. Heath, Laura Folgori

\section{SEARCH STRATEGY}

MEDLINE (Ovid MEDLINE(R) without Revisions 1996 to August Week 4 2017) and EMBASE (Embase 1996 to 2017 Week 36). Searched on 05/09/2017

1. antibiotic.mp. or exp Anti-Bacterial Agents/

2. antimicrobial.mp.

3. (anti?biot* or anti?infect* or anti?bact* or anti?microb*).mp. [mp=title, abstract, original title, name of substance word, subject heading word, keyword heading word, protocol supplementary concept word, rare disease supplementary concept word, unique identifier, synonyms]

4. anti microbial.mp.

5. exp Anti-Infective Agents/ or anti-infective.mp.

6. 1 or 2 or 3 or 4 or 5

7. exp Enterobacteriaceae/ or enterobacteriaceae.mp.

8. exp Enterobacter aerogenes/ or enterobacter.mp. or exp Enterobacter/ or exp Enterobacter cloacae/

9. exp Escherichia/ or escherichia.mp. or exp Escherichia coli/

10. klebsiella.mp. or exp Klebsiella/ or exp Klebsiella pneumoniae/ or exp Klebsiella oxytoca/

11. exp Morganella morganii/ or exp Morganella/ or morganella.mp.

12. proteus.mp. or exp Proteus/

13. serratia.mp. or exp Serratia/ or exp Serratia marcescens/

14. acinetobacter.mp. or exp Acinetobacter baumannii/ or exp Acinetobacter/

15. citrobacter.mp. or exp Citrobacter freundii/ or exp Citrobacter/ or exp Citrobacter rodentium/ or exp Citrobacter koseri/

16. exp Pseudomonas aeruginosa/ or exp Pseudomonas/ or pseudomonas.mp.

17. 7 or 8 or 9 or 10 or 11 or 12 or 13 or 14 or 15 or 16

18. extended spectrum beta-lactamases.mp.

19. ESBL.mp. 
20. exp beta-Lactamases/ or carbapenemase.mp.

21. carbapenem resistance.mp.

22. carbapenem resistant.mp.

23. drug resistance.mp. or exp Drug Resistance/

24. carbapenemase*.mp. [mp=title, abstract, original title, name of substance word, subject heading word, keyword heading word, protocol supplementary concept word, rare disease supplementary concept word, unique identifier, synonyms]

25. (carbapenem adj1 resist*).mp. [mp=title, abstract, original title, name of substance word, subject heading word, keyword heading word, protocol supplementary concept word, rare disease supplementary concept word, unique identifier, synonyms]

26. CTX-M.mp.

27. AmpC.mp.

28. MBL.mp.

29. metallo-b-lactamase.mp.

30. vim.mp.

31. NDM.mp.

32. OXA.mp.

33. oxacillinase.mp.

34. IMP.mp.

35. KPC.mp.

36. Klebsiella pneumoniae carbapenemase.mp.

37. TEM.mp.

38. SHV.mp.

39. 18 or 19 or 20 or 21 or 22 or 23 or 24 or 25 or 26 or 27 or 28 or 29 or 30 or 31 or 32 or 33 or 34 or 35 or 36 or 37 or 38

40. 6 and 17 and 39

41. 40 not animals.mp. [mp=title, abstract, original title, name of substance word, subject heading word, keyword heading word, protocol supplementary concept word, rare disease supplementary concept word, unique identifier, synonyms]

42. limit 41 to "all child (0 to 18 years)" 
Figure Supplementary 1: Flowchart and study selection

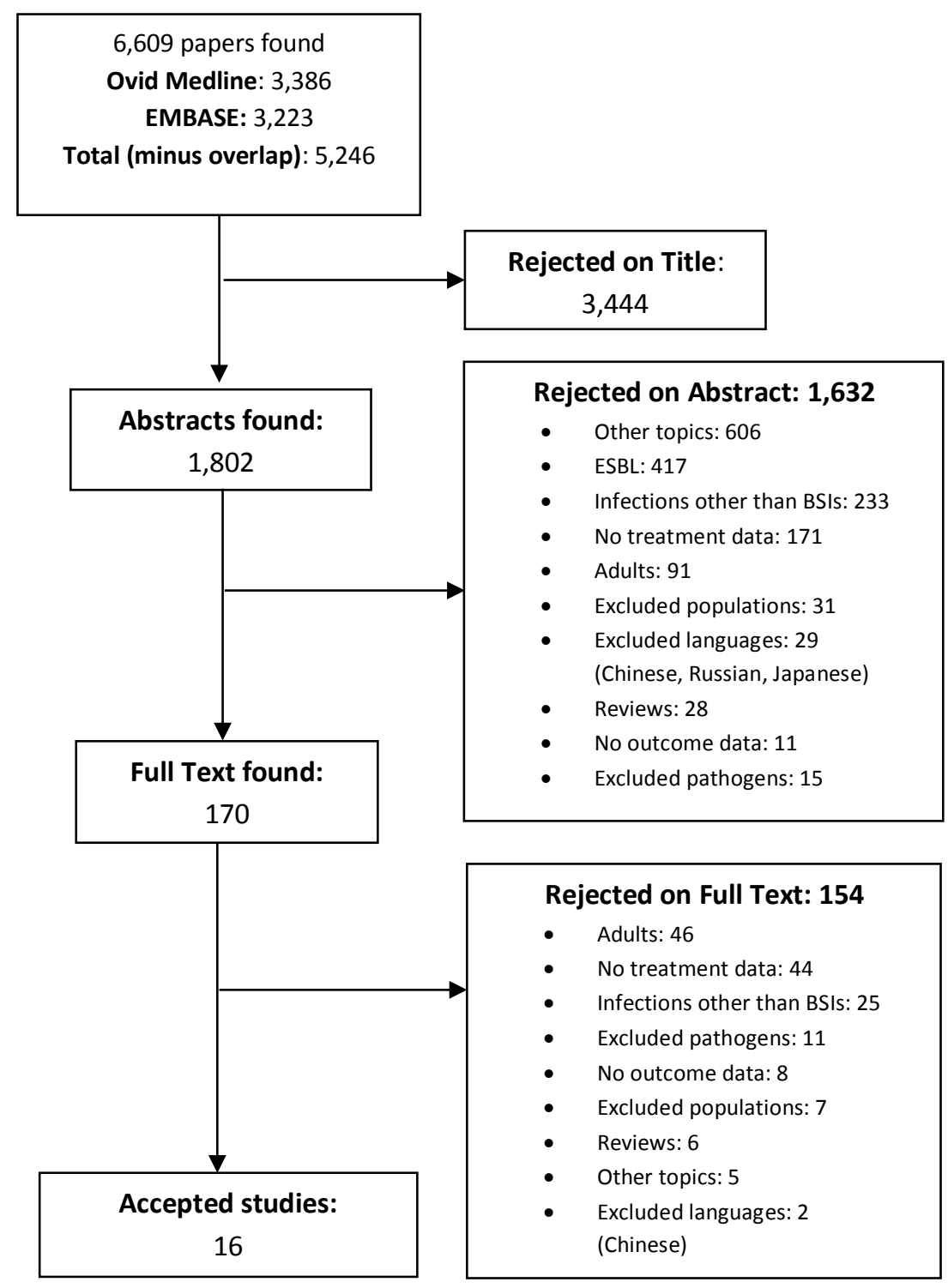

